\title{
Effect of zopiclone on sleep, night-time ventilation, and daytime vigilance in upper airway resistance syndrome
}

\author{
F. Lofaso*, F. Goldenberg*, C. Thebault**, C. Janus**, A. Harf*
}

\begin{abstract}
Effect of zopiclone on sleep, night-time ventilation, and daytime vigilance in upper air way resistance syndrome, F. Lofaso, F. Goldenberg, C. Thebault, C. Janus, A. Harf. (c) ERS Journals Ltd 1997.

ABSTRACT: We have assessed the effects of zopiclone $(7.5 \mathrm{mg})$, a new cyclopyrrolone hypnotic drug, on ventilation, sleep parameters, and daytime vigilance in snorers with upper airway resistance syndrome (UARS).

Using a randomized double-blind design, eight male patients with UARS took either oral zopiclone or a placebo each evening for seven consecutive days and then crossed over to the other drug after a 7 day placebo period. Polysomnography followed by a multiple sleep latency test (MSLT) was performed during the last night of each treatment period.

Zopiclone produced significant improvements in the sleep efficiency index (total sleep time/time in bed) (placebo $84 \pm 15 \%$ versus zopiclone $91 \pm 7 \%$ ) and average MSLT (placebo 10.3 \pm 3.7 min versus zopiclone $14.9 \pm 2.8 \mathrm{~min}$ ), as well as nonsignificant improvements in sleep onset latency and total sleep time. It had no effect on sleep architecture or on the arousal index (placebo $17 \pm 8$ arousals $h^{-1}$ versus zopiclone $17 \pm 4$ arousals ${ }^{-1}{ }^{-1}$ ). Furthermore, none of the respiratory parameters were significantly affected by zopiclone.

In conclusion, zopiclone has no adverse effects on sleep architecture, respiratory parameters during sleep, and daytime sleepiness in patients with UARS.

Eur Respir J 1997; 10: 2573-2577.
\end{abstract}

*Service de Physiologie-Explorations Fonctionnelles and Institut National de la Santé et de la Recherche Médicale INSERM U 296, Hôpital Henri Mondor, 94010 Créteil, France. **Laboratoires Rhône-Poulenc Rorer-Spécia, 92545 Montrouge, France.

Correspondence: F. Lofaso, Service de Physiologie-Explorations Fonctionnelles, Hôpital Henri Mondor, 94010 Créteil, France

Keywords: Arousal

hypnotic

respiration during sleep

sleepiness

snoring

upper airway resistance syndrome

Received: March 201997

Accepted after revision August 241997

This study was supported by the Laboratories Rhône-Poulenc Rorer-Spécia, 92545 Montrouge, France.
Obstructive sleep apnoea syndrome (OSAS) is believed to cause poor nocturnal sleep in snorers. Clinical experience and epidemiological studies indicate that OSAS is a progressive disease in which simple snoring without apnoeas gradually evolves into a disabling and even fatal condition [1]. More recently, it has been demonstrated that habitual snoring without apnoea, hypopnoea, or hypoxic dips can be accompanied by subtle disturbances in nocturnal sleep and sleep fragmentation, a condition called upper airway resistance syndrome (UARS) $[2,3]$. In this condition the arousal stimulus is the increased ventilatory effort in response to airway obstruction [4]. The sleep fragmentation of UARS can cause daytime sleepiness and difficulty in maintaining sleep. The prevalence of this new syndrome is probably high in a population of heavy snorers, and sleep fragmentation has been found in more than half the nonapnoeic subjects referred to an otorhinolaryngology clinic for snoring with social impairment [5]. Because insomnia is also a common problem in heavy snorers [6], many patients with UARS probably receive hypnotic drugs as the first approach to their condition. It is therefore important to ascertain that these drugs are associated with minimal or no effects on respiration in the population.

Hypnotics, especially long-acting benzodiazepines, are known to blunt defence mechanisms such as arous- ability [7] and to depress the respiratory centres [8,9] and upper airway dilator muscles [10]. Any of these effects could precipitate the transition from UARS to OSAS. For example, MENDELson et al. [11] reported the case of an insomniac heavy snorer who developed OSAS after receiving flurazepam $30 \mathrm{mg}$. Similarly, DoLLY and BLOCK [12] observed that flurazepam significantly modified the incidence and severity of breathing abnormalities during sleep in asymptomatic patients. It has also been suggested that benzodiazepines may be associated with increased mortality in the elderly [13]. Caution should therefore be observed when prescribing hypnotic drugs to snorers with a complaint of insomnia.

Zopiclone is a short-acting cyclopyrrolone that appears to differ clinically from benzodiazepines in several ways: it preserves slow wave sleep (SWS) [14], it does not impair daytime performance in normal subjects $[15,16]$, it has no significant effect on the control of breathing during quiet sleep, quiet wakefulness, or induced hyperventilation in patients with pulmonary disease [17], and it has only minimal deleterious effects on respiration in patients with OSAS [18].

Because it is important to document the safety of this widely used hypnotic in UARS, a study was designed to evaluate the effects of $7.5 \mathrm{mg} \cdot \mathrm{day}^{-1}$ zopiclone during 1 week, versus a placebo, on ventilation, sleep parameters and daytime vigilance in snorers with UARS. 


\section{Methods}

\section{Patients}

All included patients were subjects with UARS taken from a group of heavy snorers who complained of daytime tiredness and/or sleepiness.

Patients were excluded if physical examination, laboratory tests (serum creatinine and hepatic enzymes) electrocardiograph (ECG), vital capacity, or forced expiratory volume in one second (FEV1)/forced vital capacity (FVC) were abnormal. Subjects with a current medical illness, or a history of serious psychiatric disease or who were taking medication known to affect sleep or vigilance were excluded. Patients were also required to have a habitual consumption of no more than four caffeinecontaining beverages per day and to have no history of alcohol abuse. Beverages containing alcohol or caffeine were prohibited during the days of study.

\section{Diagnosis of UARS}

Two polysomnographic evaluations were required for the diagnosis of UARS. A home polysomnographic study was performed first to identify snorers with abnormal sleep fragmentation but no obstructive sleep apnoea (OSA) or periodic leg movements to explain this finding. A second polysomnographic study was then performed in the laboratory to demonstrate that the sleep fragmentation was due to an increase in respiratory effort in response to an increase in upper airway resistance.

The domiciliary study included recordings of electroencephalogram (C4-A1, C3-A2), electro-oculogram, chin electromyogram, electromyogram of the tibialis anterior muscle of both legs, oronasal airflow and rib cage movement (Multi-Parameter Analysis recorder 2 and Medilog 9200; Oxford Medical Instrument, Abingdon, UK), and arterial pulse oximetry (Nellcor BS; Nellcor Inc, Hayward, USA). To be eligible for the laboratory study, patients had to have a domiciliary study that met the following criteria: apnoea index $<5$ events $\cdot h^{-1}$ during sleep; apnoea-hypopnoea index $<10$ events $\cdot h^{-1}$ during sleep; oxygen desaturation index $<10$ events $\cdot h^{-1}$ during sleep; and arousal index greater than 10 events $\cdot \mathrm{h}^{-1}$ during sleep (see below for the definitions of apnoea, hypopnoea, oxygen desaturation and arousal).

The laboratory polysomnographic study included recordings of an electroencephalogram (C4-A1, C3-A2), electro-oculogram, a chin electromyogram, thoracic and abdominal movement, electromyogram of the tibialis anterior of both legs and arterial pulse oximetry (Nellcor BS; Nellcor Inc). During the laboratory study night, oronasal airflow was quantified using a tight-fitting facial mask and a Fleisch No. 2 pneumotachograph (Fleisch, Lausanne, Switzerland) connected to a differential pressure transducer (Validyne MP45 $\pm 5 \mathrm{cmH}_{2} \mathrm{O}$; Northridge, CA, USA). In addition, respiratory effort was monitored by measuring oesophageal pressure (Gaeltec; Dunvegan, Skye, UK). All signals were recorded on a 14 channel paper recorder (Electroencephalograph; Nihon Kohden, Tokyo, Japan) for subsequent analysis. The criterion for diagnosis of UARS and eligibility for the study was the presence of more than 10 nonapnoeic-nonhypopnoeic respiratory events $\cdot \mathrm{h}^{-1}$ during sleep terminated by an arousal. A nonapnoeic-nonhypopnoeic respiratory event was defined as the concomitant occurrence, in the absence of hypopnoea (airflow drop $<50 \%$ of the preceding baseline during $10 \mathrm{~s}$ and desaturation $<3 \%$ of the preceding baseline level) of both a gradual change in the shape of the inspiratory flow contour characterized by increasing limitation and an increase in the oesophageal pressure swing, with termination of the event as abrupt normalization of both the inspiratory flow contour and the oesophageal pressure swing.

\section{Zopiclone versus placebo study}

The study was approved by the Research Ethics Committee of our institution, and each patient gave consent in accordance with the requirements of the Committee.

The study was performed using a randomized, double-blind, cross-over design. The total duration of the study was 3 weeks, with two 1 week periods during which either zopiclone or a placebo was given orally in the evening, and an intervening 1 week placebo period. During the last night of each treatment period, the study patients underwent all night polysomnography followed by a multiple sleep latency test (MSLT). Medication (zopiclone or placebo) was administered immediately before lights-out. Nocturnal polysomnography started at 23:00 $\mathrm{h}$ and stopped at 06:45 h.

Polysomnography was performed in the standard way, using a 14 channel paper recorder (Electroencephalograph; Nihon Kohden), and included electroencephalography (C4-A1, C3-A2), electro-oculography, chin electromyography, electromyography of the tibialis anterior of both legs, oronasal thermistors, thoracic and abnormal movements and arterial pulse oximetry (Nellcor BS; Nellcor Inc). All sleep recordings were reviewed by the same independent examiner. Sleep staging was performed according to standard criteria [19]. Electroencephalographic (EEG) arousals were detected based on an abrupt shift in EEG frequency, including alpha and/or frequencies greater than $16 \mathrm{~Hz}$ but not spindles, and were scored according to standard criteria [20]. Thus, intrusion of alpha activity of less than $3 \mathrm{~s}$, alpha activity occurring less than $10 \mathrm{~s}$ after an arousal, and alpha activity during REM sleep, not accompanied by a concurrent increase in submental EMG amplitude do not meet the criteria of arousal. An abnormal breathing event during objectively measured sleep was defined according to commonly used clinical criteria as either complete cessation of airflow lasting $10 \mathrm{~s}$ or more (apnoea) or a reduction in oronasal airflow lasting $10 \mathrm{~s}$ or more with a drop in arterial oxygen saturation $\left(\mathrm{Sa}_{\mathrm{a}} \mathrm{O}_{2}\right)$ of at least $3 \%$ of baseline (hypopnoea). The apnoea index (AI) and hypopnoea+apnoea index (AHI), expressed as events. $\mathrm{h}^{-1}$ during sleep, were used as summary measurements of sleep-disordered breathing.

The MSLT, a standardized method used to assess daytime sleepiness [21], comprises five consecutive tests conducted at $2 \mathrm{~h}$ intervals starting at 09:00 h, and is designed to evaluate the propensity to fall asleep. In addition, at the end of the MSLT, each patient completed a questionnaire including: 1) a French version of 
the Epworth sleepiness scale (ESS) [22]; and 2) a subjective assessment of sleep by a French version of the Spiegel questionnaire.

\section{Statistical analysis}

Comparisons between the two treatments were made using paired Wilcoxon's tests. The level of significance was set at $5 \%$.

\section{Results}

Eight patients aged 34-56 yrs (mean \pm SD $46 \pm 9$ yrs) took part in the study. Their mean body mass index (BMI) was $26.3 \pm 2.4 \mathrm{~kg} \cdot \mathrm{m}^{-2}$. During domiciliary polysomnography, their AI and AHI were $1 \pm 1$ and $3 \pm 3$ events $\cdot h^{-1}$, respectively, and their arousal index was $17 \pm 7$ events $\cdot \mathrm{h}^{-1}$ during sleep. During the laboratory polysomnography performed before study inclusion, the mean oesophageal pressure swing at the end of the nonapnoeic-nonhypopnoeic respiratory events was $27 \pm 5 \mathrm{cmH}_{2} \mathrm{O}$. The index of respiratory events of (apnoea and hypopnoea included) was $21 \pm 4$ events $\cdot h^{-1}$, of which $15 \pm 3$ were terminated by an arousal according to the American Sleep Disorders Association (ASDA) criteria.

Table 1 shows the sleep architecture data for the two treatment nights. As compared with the placebo, zopiclone was associated with a significant improvement in the sleep efficiency index (total sleep time/time in bed) and with nonsignificant improvements in sleep onset latency and total sleep time. No differences were found in other indices of sleep architecture. The arousal index was similar with zopiclone and the placebo (table 1).

No patient reported a worsening of snoring with zopiclone or the placebo.

Table 2 shows that mean latency measured during MSLT was significantly increased by zopiclone as compared to the placebo.

There were no statistically significant differences between zopiclone and the placebo regarding mean scores on the ESS ( $13 \pm 5$ versus $12 \pm 6$, respectively) and the Spiegel questionnaire ( $20 \pm 4$ versus $20 \pm 4$, respectively).

Figure 1 shows that individual respiratory variables were similar with zopiclone and the placebo. The AHI did not exceed 5 events. $\mathrm{h}^{-1}$ during sleep on either of the two treatment nights, except in one patient, whose AHI was lower with zopiclone than with the placebo. In addition, the mean total duration of apnoeas and hypopnoeas
Table 2. - Multiple sleep latency test data

\begin{tabular}{lrrc}
\hline $\begin{array}{l}\text { Time of the } \\
\text { latency test }\end{array}$ & Placebo & Zopiclone & $\begin{array}{c}\text { Statistical } \\
\text { analysis }\end{array}$ \\
\hline $09: 00 \mathrm{~h}$ & $6.4 \pm 3.7$ & $9.9 \pm 6.5$ & $\mathrm{NS}$ \\
$11: 00 \mathrm{~h}$ & $6.2 \pm 5.1$ & $15.8 \pm 5.1$ & $\mathrm{p}=0.01$ \\
$12: 00 \mathrm{~h}$ & $12.7 \pm 5.0$ & $12.6 \pm 4.6$ & $\mathrm{NS}$ \\
$15: 00 \mathrm{~h}$ & $10.6 \pm 6.9$ & $16.8 \pm 4.9$ & $\mathrm{p}<0.05$ \\
$17: 00 \mathrm{~h}$ & $15.5 \pm 6.7$ & $17.9 \pm 3.4$ & $\mathrm{NS}$ \\
Mean & $10.3 \pm 3.7$ & $14.9 \pm 2.8$ & $\mathrm{p}<0.01$ \\
\hline
\end{tabular}

Values are presented as mean \pm SD in minutes.
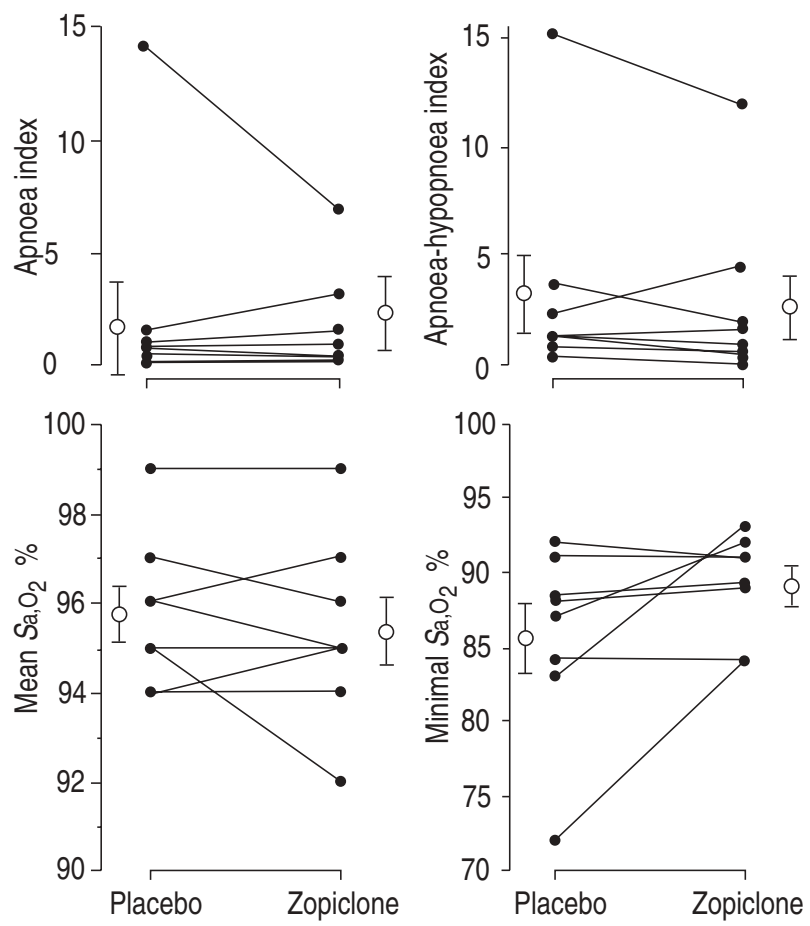

Fig. 1. - Apnoea index, apnoea-hypopnoea index, mean $\mathrm{S}_{\mathrm{a}, \mathrm{O}_{2}}$ and minimal $\mathrm{Sa}_{\mathrm{a}} \mathrm{O}_{2}$ in the eight study patients during the two polysomnography nights (placebo versus zoplicone). Mean and SEM values are shown by the open symbols and bars.

during the night was similar with zopiclone and placebo ( $6 \pm 10$ min versus $7 \pm 10 \mathrm{~min}$, respectively). Minimal $\mathrm{Sa}_{\mathrm{a}, \mathrm{O}_{2}}$ showed no differences between treatments, and zopiclone had no important individual effect on this index (fig. 1). There were no differences seen between the two treatments regarding mean $\mathrm{Sa}_{\mathrm{a}} \mathrm{O}_{2}$ (fig. 1), although one patient showed a $3 \%$ decrease with zopiclone. In this patient, minimal $S \mathrm{a}, \mathrm{O}_{2}$ was higher during the zopiclone

Table 1. - Sleep data

\begin{tabular}{lccc}
\hline & Placebo & Zopiclone & Statistical analysis \\
\hline Sleep-onset latency min & $34 \pm 67$ & $11 \pm 11$ & NS \\
REM sleep latency min & $81 \pm 55$ & $97 \pm 33$ & NS \\
Total sleep time min & $399 \pm 75$ & $421 \pm 39$ & NS \\
Total sleep time/time in bed \% & $84 \pm 15$ & $91 \pm 7$ & p $<0.05$ \\
Wake after sleep onset min & $37 \pm 24$ & $34 \pm 24$ & NS \\
Stage I \% of total sleep time & $12 \pm 6$ & $12 \pm 4$ & NS \\
Stage II \% of total sleep time & $53 \pm 6$ & $51 \pm 9$ & NS \\
Stage III \% of total sleep time & $7 \pm 2$ & $7 \pm 3$ & NS \\
Stage IV \% of total sleep time & $12 \pm 4$ & $12 \pm 9$ & NS \\
REM \% of total sleep time & $16 \pm 10$ & $17 \pm 4$ & NS \\
Arousal index event h $^{-1}$ during sleep & $17 \pm 8$ & $17 \pm 10$ & NS \\
\hline
\end{tabular}

Values are presented as mean \pm SD. REM: rapid eye movement. 
night than during the placebo night ( $84 \%$ versus $72 \%$, respectively), whereas no differences were seen for AHI (12 events $\cdot \mathrm{h}^{-1}$ versus 15 events $\cdot \mathrm{h}^{-1}$, respectively) or total duration of apnoeas and hypopnoeas (28 min versus 31 min, respectively).

\section{Discussion}

The main results of this study are that zopiclone caused no deterioration in sleep architecture, respiratory measurements or daytime vigilance in patients with UARS, as compared with a placebo.

Before discussing the implications of our findings, we will address several methodological issues. The definition of sleep fragmentation as an arousal index of more than 10 events $\cdot \mathrm{h}^{-1}$ during sleep may seem arbitrary. Although the ASDA has developed criteria for defining arousal, there is still room for subjectivity. Thus, normal subjects and normal snorers had less than 10 short EEG arousals events $\cdot \mathrm{h}^{-1}$ during sleep in some studies $[2,23]$, whereas in another study control subjects without OSA had an arousal index of 21 events $\cdot h^{-1}$ [24]. Our selection of 10 arousals $\cdot h^{-1}$ during sleep as the threshold defining sleep fragmentation was based on a recent study that we performed in 105 nonapnoeic heavy snorers [5]. In that study, slow wave sleep values were normal in middle-aged nonapnoeic snorers with an arousal index of less than 10 events $\cdot \mathrm{h}^{-1}$ (mean $7 \pm 2$ events $\cdot \mathrm{h}^{-1}$ ), but were abnormal in those with an arousal index of more than 10 events $\cdot h^{-1}$ (mean $15 \pm 5$ events $\left.\cdot h^{-1}\right)$. In addition, in another recent study, we observed that successfully treated sleep apnoea syndrome (SAS) patients had less than 10 short EEG arousals $\cdot \mathrm{h}^{-1}$ during sleep [25]. These findings show that when we used the ASDA criteria in our laboratory, arousals occurring at a rate of more than 10 events $\cdot h^{-1}$ significantly affect the architecture of nocturnal sleep.

We did not make objective measurements of snoring and we are, therefore, unable to exclude an increase in snoring with zopiclone. However, no patients reported a worsening of snoring with zopiclone or placebo.

We attempted to exclude subjects with obstructive sleep apnoea by preliminary domiciliary polysomnography. However, one of our patients met the criteria for mild SAS during the placebo study. The AHI has been shown to vary substantially from night to night in patients with mild sleep-disordered breathing [26]. Although the results from this patient may have biased our data somewhat, he was similar to the seven others in that neither his AHI nor his total duration of apnoeas and hypopnoeas increased with zopiclone. However, he was the only patient whose mean $\mathrm{S}_{\mathrm{a}} \mathrm{O}_{2}$ decreased by more than $1 \%$ during the zopiclone night as compared to the placebo. This reduction was probably due to a reduction in baseline sleep $S_{\mathrm{a}} \mathrm{O}_{2}$ since the AHI and the duration of apnoea and hypopnoeas remained unchanged with zopiclone. The most likely explanation for this reduction is a fall in resting ventilation. On the other hand, it has been demonstrated that zopiclone has no significant effects on control of breathing in patients with severe chronic obstructive pulmonary disease [17]. Nevertheless, in our seven other patients with UARS, none of the respiratory parameters were substantially affected by zopiclone (figure 1). This is in agreement with a previous study that found no worsening of moderate OSAS with zopiclone [18].

Sleep efficiency increased significantly with zopiclone and there was no decrease in SWS. These results are consistent with studies in chronic insomniacs and normal sleepers demonstrating either an increase or no change in SWS [14]. Interestingly, no decrease in the arousal index was seen with zopiclone. This suggests that the sedation provided by $7.5 \mathrm{mg}$ of zopiclone is not sufficient to increase the arousal threshold. Lending support to this hypothesis is the absence of any increase in the number or duration of apnoeas or hypopnoeas with zopiclone, with most disordered breathing events during sleep being terminated by arousal.

All the present patients complained of tiredness and/ or sleepiness. We quantified sleepiness using both the ESS, a subjective rating scale [22], and the MSLT, the only electrophysiological test that has been validated as a tool for distinguishing different degrees of sleepiness [21]. However, these methods have several limitations. The ESS is limited by individual differences in the description of subjective sleepiness. For instance, subjects have been observed to fall asleep during periods when they rated themselves as fully alert [27]. In addition, a subjective rating scale that uses a questionnaire based on the experience of specific conditions may not be well suited to the evaluation of a change in sleepiness during a period of only 7 days. In other words, despite the fact that the patients were asked to consider only the preceding 7 days, since some of the situations described by the Epworth test were not encountered within these last 7 days it is possible that the patients were simply basing the answers on their experience over a longer period of time. In contrast to the ESS, MSLT is an objective measurement in which the functional consequences of a treatment are evaluated at $2 \mathrm{~h}$ intervals during the waking portion of the day. However, it does not involve simulating the environment in which the subject may usually fall asleep. These important differences between the ESS and MSLT may explain why the results provided by these two methods were not correlated in our study. With the placebo, the mean ESS score was above normal ranges and the mean MSLT score was similar to that observed in the original study on UARS [2], i.e., slightly above the pathological range [21]. Although zopiclone did not decrease sleep fragmentation and had very few beneficial effects on sleep parameters, it was associated with a substantial improvement in MSLT. The beneficial effect of zopiclone on daytime alertness documented by the MSLT may be a specific effect of zopiclone. Improvements in daytime alertness with zopiclone have also been observed in athletes without sleep abnormalities [16], although this study did not use objective measurement of daytime alertness. Another study in normal subjects found that $7.5 \mathrm{mg}$ of zopiclone was not associated with any improvement in MSLT [15]. We found that the effects of zopiclone in UARS patients were similar to those previously reported in normal subjects [15], in that no increase in daytime sleepiness was seen from 09:00 h to 17:00 h. This finding may be ascribable to the short half-life of zopiclone and its active metabolite (range 3.5-6 h) responsible for an absence of any residual effects after 8 $\mathrm{h}$ for doses lower than $10 \mathrm{mg}$ [28]. 
In conclusion, in comparison with a placebo, zopiclone $7.5 \mathrm{mg}$ during several consecutive nights does not adversely affect sleep architecture, respiratory parameters during sleep, or daytime vigilance in patients with upper airway resistance syndrome. Furthermore, it significantly improves sleep efficiency and multiple sleep latency test. However, since arousals that may be responsible for cardiovascular disorders [5,29] are not influenced by zopiclone, it is clear that zopiclone cannot be considered an adequate treatment for UARS. Our data do suggest, however, that using zopiclone as the first approach to insomnia does not carry a risk of worsening undiagnosed UARS. To confirm these results, we recommend further studies in a larger sample of heavy snorers or UARS patients.

Acknowledgement: The authors are grateful to C. Robinet for her technical assistance.

\section{References}

1. Lugaresi E, Mondini S, Zucconi M, Montagna P, Cirignotta F. Staging of heavy snorers' disease. A proposal. Bull Eur Physiopathol Respir 1983; 19: 590-594.

2. Guilleminault C, Stoohs R, Duncan S. Daytime sleepiness in heavy snorers. Chest 1991; 99: 40-48.

3. Guilleminault C, Stoohs R, Clerk A, Cetel M, Maistros P. A cause of excessive daytime sleepiness. Chest 1993; 104: 781-787.

4. Gleeson K, Zwillich C, White DP. The influence of increasing ventilatory effort on arousal from sleep. $A m$ Rev Respir Dis 1990; 142: 295-300.

5. Lofaso F, Coste A, Gilain L, Harf A, Guilleminault C, Goldenberg F. Sleep fragmentation a risk factor for hypertension in middle-aged nonapneic snorers. Chest 1996; 109: 896-900.

6. Lugaresi E, Cirignotta F, Coccagna G, Pianna C. Some epidemiological data on snoring and cardiocirculatory disturbances. Sleep 1980; 3: 221-224.

7. Berry R, McCasland G, Light R. The effect of triazolam on the arousal response to airway occlusion during sleep in normal subjects. Am Rev Respir Dis 1992; 146: $1256-1260$.

8. Guilleminault C. Benzodiazepines, breathing and sleep. Am J Med 1990; 88: 25s-28s.

9. Murciano D, Armengaud M, Cramer P, et al. Acute effects of zolpidem, triazolam and flunitrazepam on arterial blood gases on control of breathing in severe COPD. Eur Respir J 1993; 6: 625-629.

10. Bonora M, St. John W, Bledsoe T. Differential elevation by protriptyline and depression by diazepam of upper respiratory activity. Am Rev Respir Dis 1985; 131: 4145.

11. Mendelson W, Garnett D, Gillin J. Flurazepam-induced sleep apnea syndrome in a patient with insomnia and mild sleep-related respiratory changes. J Nerv Mental Dis 1981; 169: 261-264.

12. Dolly R, Block J. Effect of flurazepam on sleep-disor- dered breathing and nocturnal oxygen desaturation in asymptomatic subjects. Am J Med 1982; 69: 75-79.

13. Fancourt G, Gastleden M. Use of benzodiazepines with particular reference to the elderly. Br J Hosp Med 1986; 35: 321-326.

14. Mouret J, Ruel D, Maillard F, Bianchi M. Zopiclone versus triazolam in insomniac geriatric patients: a specific increase in delta sleep with zopiclone. Int Clin Psychopharmacol 1990; 5: Suppl. 2, 47-55.

15. Billiard M, Besset A, de Lustrac C, Brissaud L. Doseresponse effects of zopiclone on night sleep and on nighttime and daytime functioning. Sleep 1987; 10: Suppl. $1,27-34$

16. Tafti M, Besst A, Billiard M. Effect of zopiclone on subjective evaluation of sleep and daytime alertness and on psychomotor and physical performance tests in athletes. Prog Neuro-Psychopharmacol \& Biol Psychiatry 1992; 16: 55-63.

17. Beaupré A, Soucy R, Phillips R, Bourgouin J. Respiratory center output following zopiclone or diazepam administration in patients with pulmonary disease. Respiration 1988; 54: 235-240.

18. Inoue Y, Komatsu K, Takata K, Hazama H. Comparison of zopiclone and flurazepam with mild sleep apnea. Sleep Res 1991; 20A: 325.

19. Rechtschaffen A, Kales A. A manual of standardised terminology, techniques and scoring system for sleep stages of human subjects. Washington, DC: National Institutes of Health 1968; Publication $\mathrm{N}^{\circ} 204$

20. American Sleep Disorders Association. EEG arousals: scoring rules and examples. Sleep 1992; 15: 174-184.

21. Carskadon M, Dement W, Mitler M, Roth T, Westbrook P, Keenan S. Guidelines for the multiple sleep latency test (MSLT): a standard measure of sleepiness. Sleep 1986; 9: 519-524.

22. Murray W. A new method for measuring daytime sleepiness: the Epworth sleepiness scale. Sleep 1991; 14: $540-545$.

23. Philip P, Stoohs R, Castronovo C, Guilleminault C. Sleepiness and performance under sleep fragmentation. Am Rev Respir Dis 1992; 145: A447.

24. Mathur R, Douglas N. Frequency of EEG arousals from nocturnal sleep in normal subjects. Sleep 1995; 18: 330-333.

25. Lofaso F, Lorino A-M, Duizabo D, et al. Evaluation of an auto-CPAP device based on snoring detection. Eur Respir J 1996; 9: 1795-1800.

26. Wittig R, Romaker A, Zorick F, Roehrs T, Conway W, Roth T. Night-to-night consistency of apneas during sleep. Am Rev Respir Dis 1984; 129: 244-246.

27. Wedderburn A. Sleeping on the job: the use of anecdotes for recording rare but serious events. Ergonomic 1987; 30: 1229-1233.

28. Musch B, Maillard F. Zopiclone, the third generation hypnotic: a clinical overview. In: Hindmarch, I. Musch, B. Zopiclone in clinical practice. London, Clinical Neuroscience Publishers, 1990.

29. Guilleminault C, Stoohs R, Shiomi T, Kushida C, Schnittger I. Upper airway resistance syndrome, nocturnal blood pressure monitoring, and borderline hypertension. Chest 1996; 109: 901-908. 